\title{
Dar vida aos mortos? As questões de uma tradução de obra antiga escrita em língua extinta
}

\author{
Carlos Ziller Camenietzki*
}

\begin{abstract}
Os antigos e bons autores sempre tinham o cuidado, quando aparecia uma palavra menos conhecida que levava a uma tradução mais difícil, de colocar logo a ideia que ela lhes expunha e o modo como eles a interpretaram.
\end{abstract}

Piero Vettori, Variarum lectionum libri $^{1}$.

\begin{abstract}
A primeira das grandes questões que se colocam, relativas às traduções de obras escritas há cerca de trezentos anos em língua morta, é o sentido de trazê-las ao público do inquieto século XXI. Não fora apenas o enorme fluxo e refluxo de valorização do pensamento e da literatura pregressa, mas também a gigantesca percepção celebrativa, ou depreciativa, do que foi a vida de nossos antepassados, é iniciativa temerária colocar-se a proposição de trazer ao tempo de agora um livro escrito em latim (numa época em que essa língua manifestava seus últimos estertores) tratando de uma Astronomia que se encontrava às vésperas de enormes transformações.

Fazer reviver uma obra perdida numa estante de biblioteca pública importa sempre o risco de produzir um zumbi literário. Afinal, salvo para alguns professores universitários, uns poucos religiosos antiquados, essa língua é ilustre desconhecida. O enorme valor atribuído tradicionalmente ao
\end{abstract}

${ }^{*}$ Universidade Federal do Rio de Janeiro (UFRJ)

${ }^{1}$ A tradução é de minha autoria. 
latim na Filosofia e na moral pública parece ter sido deslocado há muitas décadas, levando consigo todo o patrimônio intelectual escrito nessa língua. E ainda mais, quanto ao conteúdo, o enorme esforço de conhecimento dos céus, perpetrado por gerações e gerações de estudiosos ao longo de séculos, se desvaneceu quase que completamente quando a Astronomia encontrou uma nova síntese aceita universalmente entre os praticantes.

Assim, traduzir o diálogo Uranophilus Caelestis Peregrinus de Valentin Stanse ${ }^{2}$ não é algo que apresente um sentido imediato; algo que faça seus potenciais leitores se acotovelarem nas filas de livrarias, ademais também em fase inicial de extinção.

Como não poderia deixar de ser, o texto foi composto ao sabor do tempo e ao gosto do seu autor. Ele comporta um enorme conjunto de citações e de referências literárias a personagens, a eventos e a obras da Antiguidade que chegam a aborrecer o leitor acostumado à narrativa contemporânea, mais simples, direta e próxima dos noticiários do século XXI. Por exemplo, a dedicatória, como de costume um texto em que os autores buscavam elogiar seus mecenas, levando ao paroxismo suas exaltações, é recheada de uma grande quantidade de estórias, mitos e de personagens helênicos. A mesma estratégia expositiva vai se repetindo ao longo de todo o volume, embora menos febril. As referências sequer figuram entre as usadas pelos mais pedantes escritores do nosso tempo: haja Dédalo, Sócrates, Ícaro; haja episódios edificantes de Hércules, Marte, Juno, Saturno; haja paciência para acompanhar a leitura!

No entanto, o trabalho se justifica pelo inegável testemunho que representa do exercício de uma atividade astronômica na Bahia do século XVII, pelo esforço literário de um religioso da Companhia de Jesus, missionário no Brasil, pelas informações que contém quanto à vida intelectual e científica de Salvador. Ao certo, pode-se obstar uma desproporção entre o esforço de tradução e o minguado de resultados esperáveis, e é exatamente esse problema que se propõe à discussão.

A obra em questão é um diálogo filosófico escrito em Salvador no início da década de 1680 por um astrônomo jesuíta que veio missionário ao

\footnotetext{
${ }^{2}$ A tradução dessa obra foi realizada com apoio do Programa de Residência em Pesquisa da Biblioteca Nacional do Rio de Janeiro para o ano de 2017.
} 
Brasil vinte anos antes. O autor, Valentin Stansel, era originário da Europa do Leste e já chegou com quarenta anos de idade e com boa experiência no ensino de matemática em colégios da Companhia de Jesus e na Universidade de Praga ${ }^{3}$. Como inúmeros escritores de sua época e de sua ordem, o padre tinha um acentuado gosto por uma escrita um tanto gongórica, carregada de metáforas e de alegorias típica do barroquismo literário de final do século XVII. Além disso, em sua juventude, Stansel foi aluno de Theodor Moretti e depois se reuniu a ele em Praga, integrando um animado grupo de sábios daquela cidade ${ }^{4}$. Em sua estadia romana, já a caminho das missões, ele teve contato direto e trabalhou por alguns meses com o padre Athanasius Kircher e com o seu círculo no prestigiado Colégio Romano ${ }^{5}$. Quando Stansel chega a Portugal para se preparar para a viagem, ele se desloca pelos colégios da Companhia de Lisboa e de Élvas enquanto aprendia o português, língua necessária ao exercício das missões. Seu destino solicitado era a China, mas ele acaba embarcando para Salvador em 1663. De certo modo, o padre foi testemunha de seu século, passando sua juventude durante a Guerra dos Trinta Anos na Boêmia, chegando a Roma quase junto à Rainha Cristina da Suécia e vivendo no Alentejo durante a Guerra da Restauração de Portugal contra a Monarquia Católica da Espanha.

Embora tenha circulado bastante, Stansel guardou solidamente as principais referências filosóficas amadurecidas quando estava na Boêmia. As questões metafísicas que serviram de base para ele e para todo o seu grupo de filósofos de Praga encontram-se naqueles autores da Antiguidade tardia e da Renascença conhecidos como os grandes mestres do neoplatonismo: Proclus, Plotino, Nicolau de Cusa, Mario Victor entre diversos outros. Embora essa "escola filosófica" tenha sido um tanto desprezada pelos tempos

\footnotetext{
${ }^{3}$ Os estudos biográficos de Stansel são poucos e mais ou menos proporcionados ao impacto de sua obra no século XVII. Cf. Camenietzki 1999; Stepanec, 2007; Casanovas \& Keenan, 1993. Na atual República Tcheca foram realizados alguns estudos universitários importantes nos últimos anos. Há que se considerar também Rodrigues-Moura, 2011.

${ }^{4}$ Valentin Stansel integrou-se ao grupo de Theodor Moretti e Jan Marek Marci na Universidade de Praga. O primeiro foi um matemático jesuíta, autor de um tratado de síntese sobre as marés, o segundo foi médico e filósofo de projeção europeia.

${ }^{5}$ Athanasius Kircher foi filósofo natural de referência na Companhia de Jesus em meados do século XVII e foi o primeiro organizador do Museu do Colégio Romano, mais tarde conhecido como Museo Kircheriano. Era o principal correspondente dos missionários da Ordem que se ocupavam de Filosofia Natural no Oriente.
} 
posteriores, pode-se dizer com segurança que Stansel era um filósofo neoplatônico do século XVII.

Bastante genérica, essa classificação é pouco eloquente, mas indica algo importante sobre seus modos de análise e sobre os temas e as propostas apresentadas para a interpretação dos céus e do mundo, além de sugerir algumas características das modalidades de sua escrita ${ }^{6}$. Ou seja, Stansel não iria expor suas ideias de modo claro e distinto, conforme ficou dominante no discurso filosófico posteriormente: ele simplesmente não concebia a Filosofia nem a sua escrita dessa forma. Ou seja, suas metáforas não são apenas feitos de "estilo" ou de um embelezamento formal do texto. Para ele, é o próprio mundo que se organiza como uma totalidade em que todas as suas partes estão intrinsecamente relacionadas. Dessa maneira, cada coisa do Universo, por mais ordinária que seja, influencia todas as demais e interfere nos seus modos de existência. Seu discurso alegórico é bem mais que o exercício de um barroquismo, é a manifestação na forma literária da metafísica que governa sua compreensão do mundo. Definitivamente, Valentin Stansel não era um autor que apreciava o estoicismo renascido, nos seus estudos da natureza.

Partindo desse ponto de interpretação, sua obra torna-se algo bem mais substantivo que um amontoado de ideias ocultistas, exposto de forma contorcida.

Reconhecer que a forma literária desse diálogo se encontra em convergência fundamental com a metafísica do autor é princípio que orienta a interpretação da obra e sua tradução. Sem entender essa questão, qualquer esforço de verter o texto latino e barroco ao português contemporâneo geraria necessariamente um profundo desarranjo, um texto desarrumado e incoerente, quase incompreensível; uma daquelas formas escritas que contém palavras conhecidas, mas que não nos dizem absolutamente nada.

O trabalho de tradução de um texto dessa natureza carrega, então, o necessário conhecimento do pensamento do autor, o que não é coisa simples e realizável apenas na leitura direta do livro em questão. Há que conhecer suas outras obras, há que se ter em conta o paradigma literário adotado e os

\footnotetext{
${ }^{6}$ Já há duas décadas, Cesare Vasoli argumentava que o "Neoplatonismo" é referente bem pouco preciso para a Filosofia do Renascimento e das épocas imediatamente posteriores. Cf. Vasoli, 2002.
} 
autores que escreveram obras similares antes de Stansel e que the serviram de modelo; há que estudar os seus principais interlocutores e correspondentes; há que examinar detidamente as teorias do mundo que estavam em debate e as formas específicas de posicionamento do autor diante delas. Imenso esforço.

Mas o problema não para apenas no que é necessário ao entendimento do que o diálogo propõe em termos filosóficos. $\mathrm{O}$ autor tateava em meio a teses astronômicas importantes produzidas entre a publicação do $D e$ Revolutionibus de Nicolau Copérnico em 1543 e dos Principia Mathematica de Isaac Newton em 1687. De fato, essas obras são marcos da Astronomia dos séculos XVI e XVII, mas não foram reconhecidos imediatamente como tal, não foram aceitos como livros fundadores, ou refundadores, do conhecimento do céu logo nas primeiras décadas de sua edição. Há que se ter em conta as diversas alternativas propostas e a grande quantidade de estudiosos que produziram seus trabalhos com impacto relevante em seu tempo e que foram abandonados diante de outras teses igualmente importantes. $\mathrm{O}$ autor mais significativo disso é Tycho Brahe, que figurou como o grande astrônomo do final do século XVI - e que foi celebrado por Stansel e por aqueles do século XVII ${ }^{7}$. No entanto, os mais importantes matemáticos da época do Iluminismo e dos tempos posteriores desprezaram Tycho como alguém que procurou um compromisso entre o heliocentrismo e o geocentrismo, como alguém que buscou uma "negociação" em matéria cosmológica! Até mesmo Galileu ignorou sua obra nos Diálogos sobre os dois máximos sistemas do mundo, aparentemente sem motivo algum ${ }^{8}$. Nos anos 1630-40, o modelo Geo-Heliocêntrico de Tycho era efetivamente a grande vedete astronômica dos estudiosos.

\footnotetext{
7 Tycho Brahe foi autor de uma cosmologia muito bem recebida desde o final do século XVI. Seu sistema do mundo propunha a centralidade da Terra, com a Lua e o Sol girando ao seu redor, e os demais planetas girando ao redor do Sol. Sua proposta abriu um campo vasto de interpretações e de debates até o final do século seguinte, permitindo excluir do céu as esferas cristalinas que carregariam os astros e facilitando a reflexão sobre o conceito de inércia.

${ }^{8}$ Nesta obra, os dois sistemas de mundo são o Ptolomaico e o Copernicano. O sistema policêntrico de Tycho é solenemente ignorado, embora fosse o modelo mais debatido entre os astrônomos. Cf. Galilei, 2001.
} 
Nas décadas seguintes, mas sobretudo no século XVIII, todos aqueles que haviam se dedicado à Astronomia, mas que não seguiram a linha dominante de afirmação da centralidade solar, foram considerados pelas gerações posteriores de sábios como antiquados conservadores, gente que mais atrapalhava que ajudava o desenvolvimento das ideias científicas; ou ainda como covardes que se submetiam temerosos a supostos ditames de uma Igreja "onipotente" e "onisciente". Com isso, o próprio Tycho, mas também Riccioli, Argolo, Lansberge, Borri, Muñoz, Nunes e muitos mais desapareceram da melhor bibliografia sobre o passado da Astronomia e se transformaram em ilustres desconhecidos até mesmo de diversos historiadores da disciplina. Salvou-se Kepler, aliás ex-aluno de Tycho no observatório de Uraniburgo.

Some-se a isso o dado de que quase todos os matemáticos desse tempo partilhavam, em algum nível, uma crença astrológica. Afinal, dominava entre a gente sábia uma compreensão de que as estrelas e os céus interferiam de alguma forma na vida terrena, no mínimo pela partição dos dias e das noites, das estações do ano etc. Porém, os tempos posteriores trataram esses estudos como uma abominação, como se os caminhos que levaram à "verdade" astronômica pudesse prescindir da Astrologia, e seus cultores do passado foram lançados no mais escuro dos refúgios intelectuais em nosso sábio século XX. Stansel era desses astrônomos.

Em termos mais técnicos, essas características agregam problemas severos ao trabalho de tradução por combinar um vocabulário, já em si complexo, mas também carregado de conceitos em desuso há séculos nas próprias disciplinas afetas. Essa dificuldade certamente é superável com o uso de antigos vocabulários e dicionários de Astronomia e de latim; porém agrega elementos de mais difícil superação quando apresentados em textos filosóficos em forma dialogada. As diversas passagens em que os personagens do diálogo expressam sentimentos e apreensões ficam bastante prejudicadas por força desse arcaísmo. Por exemplo, a parte em que Stansel expõe o céu empíreo dos beatos vem apresentada com uma grande discussão sobre o tamanho da Cidade Celeste e sobre a decoração de seu palácio; ali também entra uma breve referência às constelações e aos seus significados numa interpretação cristã bastante característica. No entanto, o sentido das alegorias 
se enfraquece porque nosso tempo e nossa cultura não mais vive o nome das constelações, as partições, a decoração de um palácio e a modelagem de uma cidade da mesma forma que o autor e seus primeiros leitores.

Se ainda for possível imaginar um quadro mais complexo, o padre Stansel era jesuíta! Não fossem os esforços de abnegados historiadores dos últimos quarenta anos, a imagem da antiga Companhia de Jesus ainda estaria presa àquilo que a intelectualidade laica do passado próximo disse sobre eles e sobre um suposto papel nefasto dessa ordem religiosa no desenvolvimento da ciência e da Filosofia. Por outro lado, no Brasil, a imagem dominante dos jesuítas está demasiadamente presa ao que seria uma proteção das populações nativas diante da fúria colonizadora sobre uma mão de obra facilmente redutível à escravidão. De fato, essa caracterização está centrada num problema crucial que nos acompanha até o século XXI, mas não esgota os feitos da Companhia. Mundo afora, no entanto, os padres de Santo Inácio já foram caracterizados como uma "milícia do Papa", um verdadeiro exército tridentino no enfrentamento às religiões reformadas. Em matéria filosófica e científica, os jesuítas ainda foram caracterizados como os mais empedernidos defensores de um "absolutismo monárquico" e também como os educadores de gerações, que distorciam a Filosofia Clássica da Antiguidade grega e latina. De fato, nos séculos XVIII, XIX e em boa parte do século XX, a memória dos inacianos junto aos homens de saber não é das melhores. No entanto, mais recentemente, um largo grupo de eruditos laicos de diversos países se debruçou sobre os trabalhos dos padres de Santo Inácio e seus esforços acabaram corroendo essas noções herdadas de um passado de agudos combates aos "homens de preto". De certa forma, a tradução do livro do padre Stansel é parte desse trabalho.

Diante de problemas tão difíceis, colocar essa obra em uma linguagem do século XXI apresenta sentidos bastante importantes que justificam perfeitamente o esforço. Em primeiro lugar, o livro é prova material de que a vida cultural baiana incorporava alguma investigação científica, corroborando a ideia de que os europeus, em particular os jesuítas, levaram consigo essas práticas nos seus diversos projetos de ocupação do mundo.

Em segundo lugar, trata-se de um diálogo astronômico escrito em Salvador por um matemático que colaborou efetivamente com a renovação 
astronômica do seu tempo. Ele manteve correspondência com os sábios jesuítas de diversas cidades do Velho mundo, manteve ainda boas relações intelectuais com membros da Royal Society de Londres ${ }^{9}$. Suas observações de cometas foram bastante importantes na caracterização desses fenômenos como astros que se localizavam além da Lua ${ }^{10}$. Afinal, Stansel observava os cometas do hemisfério sul da Terra e as pequenas variações de posição com relação às observações europeias indicavam que eles deveriam estar muito distantes, para além da órbita de Marte. Ou seja, o padre contribuiu, ainda que modestamente, na resolução de um dos grandes problemas astronômicos do século XVII. Embora esperável, isso não é desprezível.

Além disso, o próprio padre reclamou de seu isolamento em cartas enviadas à Europa, embora ele contasse com a rede intelectual da Companhia de Jesus lhe fornecendo notícias e livros. Mesmo com esse recurso, por si só suficiente para se manter razoavelmente informado em Salvador, a cidade era um ponto de passagem para as navegações ao Oriente e, para além do interesse comercial óbvio, inúmeros sábios da Europa se dirigiam à Índia e à China em seus esforços de conhecimento do mundo e das culturas. Não deveria ser muito raro ver aportar na cidade grupos de filósofos naturais destinados ao Oriente. De fato, nessa obra, o padre narra a chegada em Salvador de filósofos franceses que se dirigiam à ilha de Madagascar. Esses viajantes lhe teriam presenteado uma luneta de quatro lentes e um exemplar dos Princípios da Filosofia de Descartes, em troca, Stansel lhes teria dado um cesto de flores e sementes. Bela metáfora da condição do Novo Mundo vista pelos sábios. O livro fundamental de Descartes certamente chegou às mãos do jesuíta antes de $1674^{11}$. De fato, os cerca de trinta anos que separam a primeira edição dessa obra de sua provável leitura na Bahia, não é muito tempo,

\footnotetext{
${ }^{9}$ O periódico da Royal Society publicou um texto de Stansel relativo ao cometa de 1669. A citação foi parar na obra maior de Isaac Newton, os Principia Mathematica, publicado em 1687.

${ }^{10} \mathrm{Um}$ dos maiores problemas astronômicos do século XVII estava associado diretamente aos cometas, sua localização e distância à Terra. Observações rigorosas feitas no hemisfério sul podiam afastar definitivamente a tese da localização sublunar dos cometas: caso ele fosse observado no sul, ocupando a mesma constelação em que foi visto no norte, o astro não poderia estar abaixo da Lua.

${ }^{11}$ Nesse ano de 1674, Stansel havia enviado uma obra a Roma pedindo autorização para publicação. O pedido foi recusado por conta dos argumentos cartesianos apresentados pelo autor e retirados precisamente do livro Os Princípios da Filosofia.
} 
considerando que se trata de um texto de Filosofia, que não se difundiu imediatamente na Europa.

Em terceiro lugar, o padre descreve brevemente a cidade de Salvador e narra episódios importantes como uma tentativa de ataque de piratas e o seu enfrentamento vitorioso pelas forças locais. Ele mostra ainda o medo dos ataques furtivos de índios tapuias, das onças e outros animais selvagens que circulavam ao redor da cidade. Ou seja, a obra nos apresenta características importantes da vida soteropolitana do século XVII.

Esse padre realmente não era o tipo ideal de jesuíta desejado para a Província do Brasil. Stansel não se dedicava aos aldeamentos, ele sequer conhecia a língua dos indígenas e pouco se importava com isso. Tão pouco o padre era daqueles pregadores fervorosos, como os variados de que a Província do Brasil dispunha, Stansel não possuía a verve de Antônio Vieira, de Antônio de Sá ou de Simão de Vasconcelos; ele também não poderia ser visto entre os exemplos de virtude mística do Brasil. Decididamente, não era um grande administrador: a natureza tropical que ele tanto admirava não foi capaz de convertê-lo em um bom gestor das fazendas e dos engenhos da Companhia. Em Salvador ele ensinava Teologia Moral no colégio e certamente formava estudantes de matemáticas para lhe ajudar em seus trabalhos. Stansel era filósofo, e bom filósofo.

Por conta disso, a imagem tradicionalmente aceita da ação dos inacianos ganha contornos mais largos. Além daqueles esforços ligados ao tratamento dos nativos - sem dúvida, o problema mais urgente para eles e para a sociedade que se organizava - e da manutenção de suas próprias atividades, os jesuítas também se ocuparam de temas importantes das sociedades europeias, como a formação intelectual e moral de jovens da cidade e das vizinhanças, o estudo da natureza e dos céus, da manipulação das drogas locais entre muitos outros.

O padre mostra essa sua condição em alguns episódios narrados na sua obra, em particular na descrição do aparecimento do Ypupiara numa praia do recôncavo. O ser fantástico, meio-peixe e meio-homem, já integrado aos relatos fabulosos do Brasil desde o século XVI, foi despertado, morto e devorado pelos índios, sem que o sábio pudesse examiná-lo. Stansel não se preocupa com os problemas que um tal bicho poderia causar aos moradores, 
não questiona as informações recebidas sobre ele nem o seu sentido para os nativos. O padre apenas lamenta não ter podido conhecer melhor a anatomia e a vida do Ypupiara.

Essas breves considerações já são suficientes para assegurar que o esforço de tradução dessa obra é bem recompensado. Para além das suas características próprias, há ainda a importante consideração de que não há muitos livros escritos no Brasil que vieram a ser publicados no século XVII, sobretudo livros de Filosofia. É importante lembrar que o exercício sistemático e escolar dessa disciplina na América Portuguesa é tardio: quando saiu a edição do livro, o Novo Mundo já contava com três universidades: em Lima, no México e na Nova Inglaterra. A Universidade de Lima e a do México foram fundadas apenas poucos anos após a criação do Colégio de Salvador.

O Uranófilo certamente é um diálogo de interesse também por essa razão, ao menos por mostrar que a expansão europeia que desarrumou a vida e a economia de milhões de homens no mundo, na África, nas Américas, no Oriente, também levou seus sábios aos recantos mais distantes do planeta, onde eles fizeram seus estudos. E, o que é mais importante, seus resultados foram incorporados ao enorme esforço coletivo de construção da Ciência Moderna.

\section{Referências}

CAMENIETZKI, Carlos Ziller. Esboço biográfico de Valentin Stansel. Ideação, vol. 3, n. 1, p. 159-182, 1999.

CASANOVAS, Juan; KEENAN, Philip. The Observations of comets by Valentine Stansel, a seventeenth century missionary in Brazil. Archivum Historicum Societatis Iesu, vol. LXII, p. 319-30, 1993.

DESCARTES, René. Principia philosophiae. Amsterdam: Elzevir, 1644.

GALILEI, Galileu. Diálogo sobre os dois máximos sistemas do mundo, ptolomaico e copernicano. São Paulo: Discurso Editorial, 2001.

NEWTON, Isaac. Philosophiae naturalis principia mathematica. Londres, 1687.

Philosophical Transactions, 1674. 
RODRIGUES-MOURA, Henrique. Engenho poético para cantar um artifício engenhoso. $\mathrm{O}$ astrolábio de Valetim Estancel nos versos de Botelho de Oliveira e Gregório de Matos. Navegações, Porto Alegre, vol. 4, n. 2, p. 151-166, 2011.

STEPANEC, Pavel. Valentin Stansel - um observador tcheco no céu brasileiro. Ibero-Americana Pragensia, v. XLI, p. 189-204, 2007.

STANSEL, Valentin. Uranophilus caelestis peregrinus. Gand: Graet, 1685.

VASOLI, Cesare. Le filosofie del rinascimento. Milão: Mondadori, 2002. VETTORI, Piero. Variarum lectionum libri. Florença: Iunctas, 1582.

\section{Resumo}

A tradução da obra Uranophilus Caelestis Peregrinus do padre Valentin Stansel coloca sérias questões sobre sua oportunidade e importância na caracterização do que foi a vida científica na Bahia durante a segunda metade do século XVII. O livro é um diálogo astronômico em que o padre trata de diferentes temas científicos e mostra admiração pela natureza tropical. Sua escrita alegórica escapa aos padrões cartesianos, reforçando seu alinhamento ao pensamento neoplatônico de seu tempo. Seu trabalho foi importante e desfrutou de boa aceitação entre os matemáticos do Velho Mundo.

Palavras-chave: Valentin Stansel; Diálogo filosófico; Tradução científica.

\section{Résumé}

La traduction d'Uranophilus Caelestis Peregrinus du père Valentin Stansel soulève de sérieuses questions quant à sa pertinence et à son importance dans la caractérisation de la vie scientifique bahianaise dans la seconde moitié du XVIIe siècle. Le livre est un dialogue astronomique dans lequel le prêtre discute de divers sujets scientifiques et montre son admiration pour la nature tropicale. Son écriture allégorique échappe aux normes cartésiennes, renforçant as proximité à la pensée néoplatonicienne de son temps. Son travail était important et bien accepté par les mathématiciens de l'Ancien Monde.

Mots-clés: Valentin Stansel ; Dialogue philosophique ; Traduction scientifique. 